\title{
Looking for a Rarity: Histiocytic Sarcoma
}

\author{
Joana de Castro Rocha, Isabel Paiva, Ana Rita Cruz \\ Internal Medicine, Centro Hospitalar do Porto, Porto, Portugal \\ Email: joanadecastro.r@gmail.com
}

Received 21 December 2015; accepted 19 February 2016; published 22 February 2016

Copyright (C) 2016 by authors and Scientific Research Publishing Inc.

This work is licensed under the Creative Commons Attribution International License (CC BY). http://creativecommons.org/licenses/by/4.0/

\section{(c) (i) Open Access}

\begin{abstract}
Histiocytic sarcoma is an extremely rare and very aggressive malignancy, with poor prognosis. The cases described in the literature are few and the treatment is not currently considered consensual. The clinical presentation is very variable. Its characterization is made based primarily on the histology. The authors present a case of an 82-year-old woman, with multiple adenopatic retroperitoneal and left iliac conglomerates, with left leg associated edema (extrinsic compression by conglomerates). After intensive study and approach ganglion biopsy, the histologic diagnosis revealed a histiocytic sarcoma.
\end{abstract}

\section{Keywords}

Histiocytic Sarcoma, Rarity, Aggressive Malignancy, Lymphadenopathy

\section{Introduction}

Histiocytic sarcoma is a very aggressive [1] malignant [2]-[5] and rare lymphoide tissue [6] with poor prognosis [4]. It is derived from histiocytes and it may result from stem cell transformation in neoplastic hematologic disease [3] [4]. It represents less than $1 \%$ of hematolinfoid neoplasms [6]. The diagnosis is essentially based on clinics, pathology and immunohistochemistry [2]. The clinical disease onset usually represents with weigth loss, skin lesions and hepatosplenomegaly [5] but it can also be atypical.

The histiocytic sarcoma can occur at any age and can involve several parts of the body [5]. Most cases are originated in lymph nodes, but the skin and gastrointestinal tract are often other possible places of frequent origin [5]. Most rarely, in literature, is the achievement of the pleura [6], stomach [7], bone marrow [4] and lung [3] [8], and there is one case reported in mouse with liver involvement [1].

There are histologic typical markers such as CD68, lysozyme, CD4 and CD163 and the T cell receptor and immunoglobulin germline genes are usually considered. Clonal rearrangements of antigen-receptor genes have been identified in some cases, but are not essential to the diagnosis.

The differential diagnosis of histiocytic sarcoma must be done with Langerhans cell histiocytosis, hemophagocytic lymphohistiocytosis, lymphoma, carcinoma and metastatic melanoma [9]. 


\section{Case Report}

The authors present a case of a women with 82 years old, autonomous, with a known history of hypertension, peripheral venous insufficiency, depressive syndrome and also a pulmonary tuberculosis history in the youth. A ductal adenocarcinoma of the left breast was diagnosed 12 years before and she was submited to radio Therapy, but had chemotherapy intolerance.

She went to the urgency department because of behavioral changes with disorientation and mental confusion. On physical examination she was hemodinamically stable, but with abdominal tenderness hypogastric region and left iliac side with no peritoneal irritation. She had also an asymmetric edema of the left leg with the presence of erythema. The analytic study revealed inflammatory syndrome (leukocytosis $23.18 \times 10^{3} / \mathrm{uL}$; neutrophilia $21.74 \times 10^{3} / \mathrm{uL}$; elevated C reactive protein $\left.161 \mathrm{mg} / \mathrm{L}\right)$ and hyponatremia $(126 \mathrm{mmol} / \mathrm{L})$.

It was performed an abdominal ultrasound that showed adenopatic conglomerates in the upper retroperitoneum and left iliac chains (most of $5 \times 2 \mathrm{~cm}$ in diameter). Thoraco abdomino pelvic computed tomography revealed adenopatic conglomerates from the left inguinal region (most with $9 \mathrm{~cm}$ ) followed by adenopatic conglomerate in external, internal and common iliac left chains, and retroperitoneal adenopatic conglomerate that conditions encasement of great vessels and also left retrocrural lymphadenopathy (Figure 1).

Craneo encefalic computed tomography revealed no acute changes.

The clinical picture of symptomatic hyponatremia was understood in probable relationship to iatrogenic effects of the antidepressant drug she was taking since the study revealed hypotonic euvolemic hyponatremia, and it was treated with fluid therapy and discontinuation of the drug. Moreover, the analytical inflammatory syndrome was interpreted as related to cellulitis of the leg and it was treated with intravenous antibiotics with resolution of cutaneous infection. Edema was interpreted in more probable relationship to extrinsic compression by adenopatic conglomerates described before.

Quantiferon-TB came undetermined $(0.01 \mathrm{UI} / \mathrm{mL})$ but with no response to mitogen.

Because of the high suspicion of cancer, it was performed a peripheral blood immunophenotyping that was unrelated to changes suggestive of lymphoproliferative disease. It was performed as well a left inguinal node biopsy that had immunophenotyping mentioning nodal involvement by lymphoproliferative disease $\mathrm{B}$ with features suggestive of follicular B lymphoma. Histological study approach was compatible with malignancy, with standard large pleomorphic cels organized in nests and with abundant eosinophilic cytoplasm with rounded nuclear and proeminent nucleoli. It had positivity staining for S100, vimentin, lysozyme, CD45, CD68, and negative for AE1/AE3, CAM 5.2, CK7, HMB45, Melan A, myeloperoxidase, CD20, CD30 and CD3, concluding that it was consistent with histiocytic sarcoma according to the morphological and immunohistochemical findings. The study of molecular genetics showed detection of BCL2-IgH fusion gene in Mbr region.

The patient had a prolonged hospitalization and clinical complication because of her immunocompromised study (caused by cancer). She developed a nosocomial pneumonia that caused a septic shock that did not respond to treatment and was responsible for her death. The results of histology only became knowledged after death, so it was not possible to have a therapeutic approach of it.
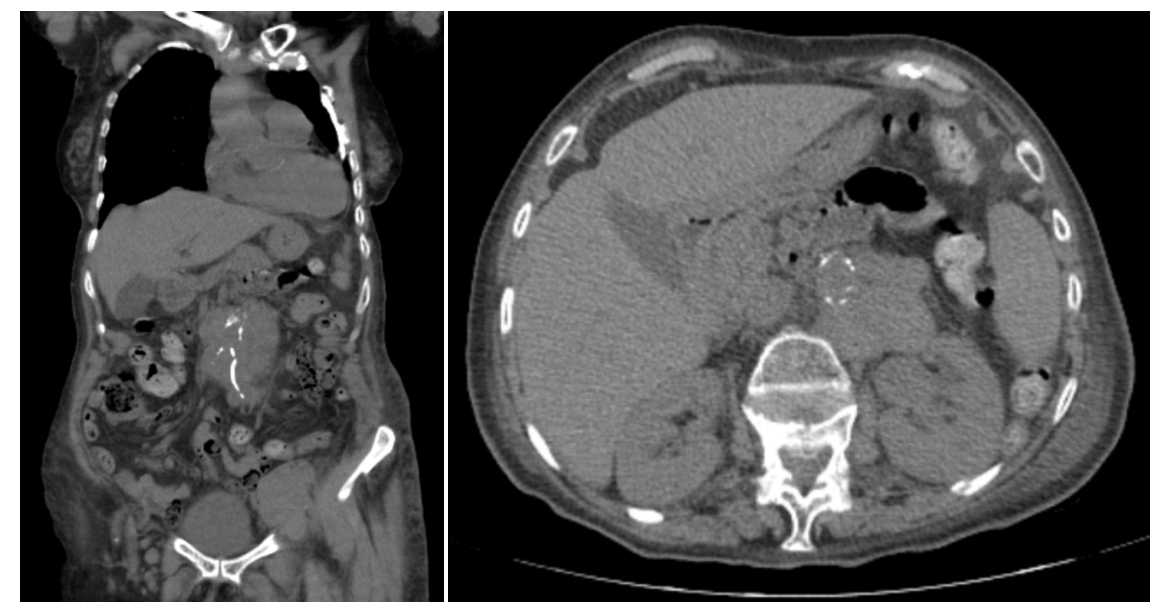

Figure 1. Computed tomography. 


\section{Discussion}

Histiocytic sarcoma is a malignant neoplasm with varied clinical presentation and with single or multisystem involvement. Its diagnosis is difficult and requires a comprehensive study with immunology and immunohistochemistry. Histologically, it presents with large cell proliferation, rounded cells, with abundant eosinophilic cytoplasm and also with eccentrically located nuclei that could be large, round, oval or irregularly shaped [10].

For immunohistochemistry, it is necessary positivity for the marker CD45 and two or more histiocytic differentiation markers (CD68, CD163, lysozyme, XIIIa factor, CD14, CD4, CD11c), plus negativity for dendritic cell markers (CD21, CD35, CD23, CD1a) [10]. However, it may exist immunophenotypic overlap because this sarcoma can originate by dendritic and histiocytic cells; by this fact, it may appear positive overlapped with other markers. Still, there should be negative for CD20 and CD3. They also must be negative for HMB45 and Melan A markers, excluding melanoma diagnosis; must be negative cytokeratins, excluding this way poorly differentiated carcinoma; must be negative CD30 and EMA markers, excluding anaplastic lymphoma; and finally must be negative for CD21, CD35 and CD23, so that we can exclude follicular dendritic cell sarcoma [10]. The positivity for the CD4 marker could arise, although it is expected to be negative [10].

The case presented by the authors refers to a woman of 82 years old with multiple adenopatic conglomerates, whose study reveals to be a histiocytic sarcoma (confirmed by histological markers). The authors emphasize the difficulty of the diagnosis, in particular regarding the possibility of lymphoma that was notorious by the immunophenotypic results and molecular genetics. There was not a possibility of discussion and also about the therapeutic intervention because of the early death of the patient when serious nosocomial infection occured.

It is known that therapeutic approach is not consensual, because there are very few reported cases and little clinical experience in diagnosing and treating it. The high aggressiveness rate of proliferation of this cancer, leads to a poor prognosis [10]. There is a description of possible therapeutic approaches in surgery (only localized tumor, but very infrequently), radiotherapy, chemotherapy or combined therapies [10].

Unfortunatetly, there was no place to do an interventional trial in this case. However, we left it described in a form of a clinical paper in order to continue the study of future investigations of a so rare entity and with little experience on that.

\section{References}

[1] Coble, D.J., Shoemaker, M., Harrington, B., Dardenne, A.D. and Bolon, B. (2015) Histiocytic Sarcoma and Bilateral Facial Vein Trombosis in a Siberian Hamster (Phodopus sungorus). Comparative Medicine, 65, 127-132.

[2] Wang, H., Zhang, J., Tao, Q., Bian, H., Shen, Y., Li, Y., Tao, L., Wang, C., Wang, Y. and Zhai, Z. (2015) Flow Cytometry Used to Identify Histiocytic Sarcoma: A Case Report. Cytometry Part B: Clinical Cytometry. http://dx.doi.org/10.1002/cyto.b.21262

[3] Mehrotra, S. and Pan, Z. (2015) Fine Needle Aspiration Cytology of Histiocytic Sarcoma with Dendritic Cell Differentiation: A Case of Transdifferentiation from Low-Grade Follicular Lymphoma. Diagnostic Cytopathology, 43, 659-663. http://dx.doi.org/10.1002/dc.23285

[4] Alten, J., Klapper, W., leuschner, I., Eckert, C., Beier, R., Vallo, E., Krause, M., Claviez, A., Vieth, S., Bleckmann, K., Moricke, A., Schrappe, M. and Cario, G. (2015) Secondary Histiocytic Sarcoma May Cause Apparent Persistent or Recurrence of Minimal Residual Disease in Childhood Acute Lymphoblastic Leukemia. Pediatric Blood \& Cancer, 62, 1656-1660. http://dx.doi.org/10.1002/pbc.25523

[5] Mallya, V., Bansal, A. and Kapoor, S. (2014) Fine Needle Aspiration of Histiocytic Sarcoma. Journal of Cytology, 31, 205-206. http://dx.doi.org/10.4103/0970-9371.151133

[6] Ganapule, A.P., Gupta, M., Kokil, G. and Viswabandya, A. (2014) Histiocytic Sarcoma with Acute Lymphoblastic Leukemia a Rare Association: Case Report and Literature Review. Indian Journal of Hematology and Blood Transfusion, 30, 305-308.

[7] Hanaoka, T., Jingu, K., Tochigi, T., Hoshino, I., Uematu, T. and Matsubara, H. (2015) A Case of G-CSF-Producing Histiocytic Sarcoma of the Stomach. International Surgery, 100, 568-573. http://dx.doi.org/10.9738/INTSURG-D-14-00023.1

[8] Tomita, S., Ogura, G., Inomoto, Kajiwara, H., Masuda, R., Iwazaki, M., Kojima, M. and Nakamura, N. (2015) Histiocytic Sarcoma Originating in the Lung in a 16-Year-Old Male. Journal of Clinical and Experimental Hematopathology, 55, 45-49. http://dx.doi.org/10.3960/jslrt.55.45

[9] So, H., Kim, S.A., Yoon, D.H., Khang, S.K., Hwang, J., Suh, C.H. and Suh, C. (2015) Primary Histiocytic Sarcoma of 
the Central Nervous System. Cancer Research and Treatment, 47, 322-328.

[10] Kondo, R.N., Araújo, F.M., Ogama, A. and Minelli, L. (2013) Sarcoma histiocitico cutâneo: Neoplasia rara e de difícil diagnóstico. Moreira Jr Editora/RBM Revista Brasileira de Medicina, 70. 